\title{
LEVANTAMENTO GEOLÓGICO E PETROGRÁFICO NA ILHA DO MONTE DE TRIGO (LITORAL NORTE DE SÃO PAULO, BRASIL)*
}

\author{
JOSÉ MOAGYR VIANNA COUTINHO** e GERALDO CONRADO MELCHER***
}

\begin{abstract}
The small island of Monte de Trigo, $10 \mathrm{~km}$ offshore of northern São Paulo coast has been geologically and petrographycally studied. The island is part of an alkaline massif in which theralites and foyaites are the major lithologies and the only plutonic types represented. Hypabissal types are always dykes cutting indifferently the two major plutons. A large variety of alkaline lamprophyres are here represented especially by monchiquites but there are other meso and melanocratic rocks such as syenobasalts and microshonkinites as well as leucocratic dyke rocks; phonolite and rhomb porphyry. One thick dyke occurrence is actually a magmatic trachitic breccia containing fragments of theralitic and foyaitic parentage as well as gneissie or granitic material not to be seen anywhere else in the island.

Geological and petrographical descriptions are given and many modal and three chemical analyses are furnished but there are not enough elements to draw petrogenetic conclusions.
\end{abstract}

INTRODUÇÃo Em janeiro de 1966, os autores tiveram a oportunidade de visitar a Ilha do Monte de Trigo, ocasião em que coletaram amostras de rochas alcalinas e realizaram um levantamento litológico e estrutural ao longo da costa insular. Verificado o interesse científico das ocorrências com a caracterização de numerosos tipos petrográficos e, em especial, dois corpos intrusivos principais, foiaítico e teralítico, empreendeu-se nova viagem objetivando coletar material para análise química e levantamento de contatos entre os dois corpos ígneos principais. Esse último trabalho foi efetuado por Walter Hildebrandt e José Nakashima, então estudantes, a quem agradecemos a colaboração.

O trabalho apresenta os resultados obtidos no reconhecimento geológico na linha de costa da Ilha, estudo petrográfico das litologias encontradas, três análises químicas de rochas representativas e dados ópticos de alguns minerais que apresentaram maior interesse. Por falta de tempo na ocasião e oportunidade posterior, não foram percorridos: o interior da Ilha (com exceção da Ponta Negra) e $1300 \mathrm{~m}$ de linha de costa; $500 \mathrm{~m}$ a NW até $800 \mathrm{~m}$ a NE da Ponta Sul. Entretanto a litologia simples (foiaítos) dessa região foi identificada à vista desarmada e à distância de 10 a $20 \mathrm{~m}$ durante viagem de contorno, feita em bote. Esse trecho é coberto por volumosos matacões arredondados, de granulação grossa e claros, tipicamente sieníticos. Desse modo, julgamos completa e segura a interpretação litológica do contorno da Ilha tal como aparece na Fig. 1. Mas, nesse trecho, não percorrido a pé, ignora-se a existência e densidade de ocorrências restritas, principalmente diques.

Dados geográficos A Ilha do Monte de Trigo tem seu ponto culminante coincidindo aproximadamente com seu centro geográfico, localizado à latitude $23^{\circ} 51^{\prime} 49^{\prime \prime} \mathrm{S}$ e longitude $45^{\circ} 46^{\prime} 54^{\prime \prime}$ W.G. Situa-se ao largo do litoral norte do Estado de São Paulo, de cujo ponto

* Com auxílio do Conselho Nacional de Pesquisas

**Departamento de Mineralogia e Petrologia, Instituto de Geociências, Universidade de São Paulo. Caixa Postal 20 899, São Paulo, Brasil

***Departamento de Engenharia de Minas, Escola Politécnica, Universidade de São Paulo. Caixa Postal 8174 , São Paulo, Brasil 


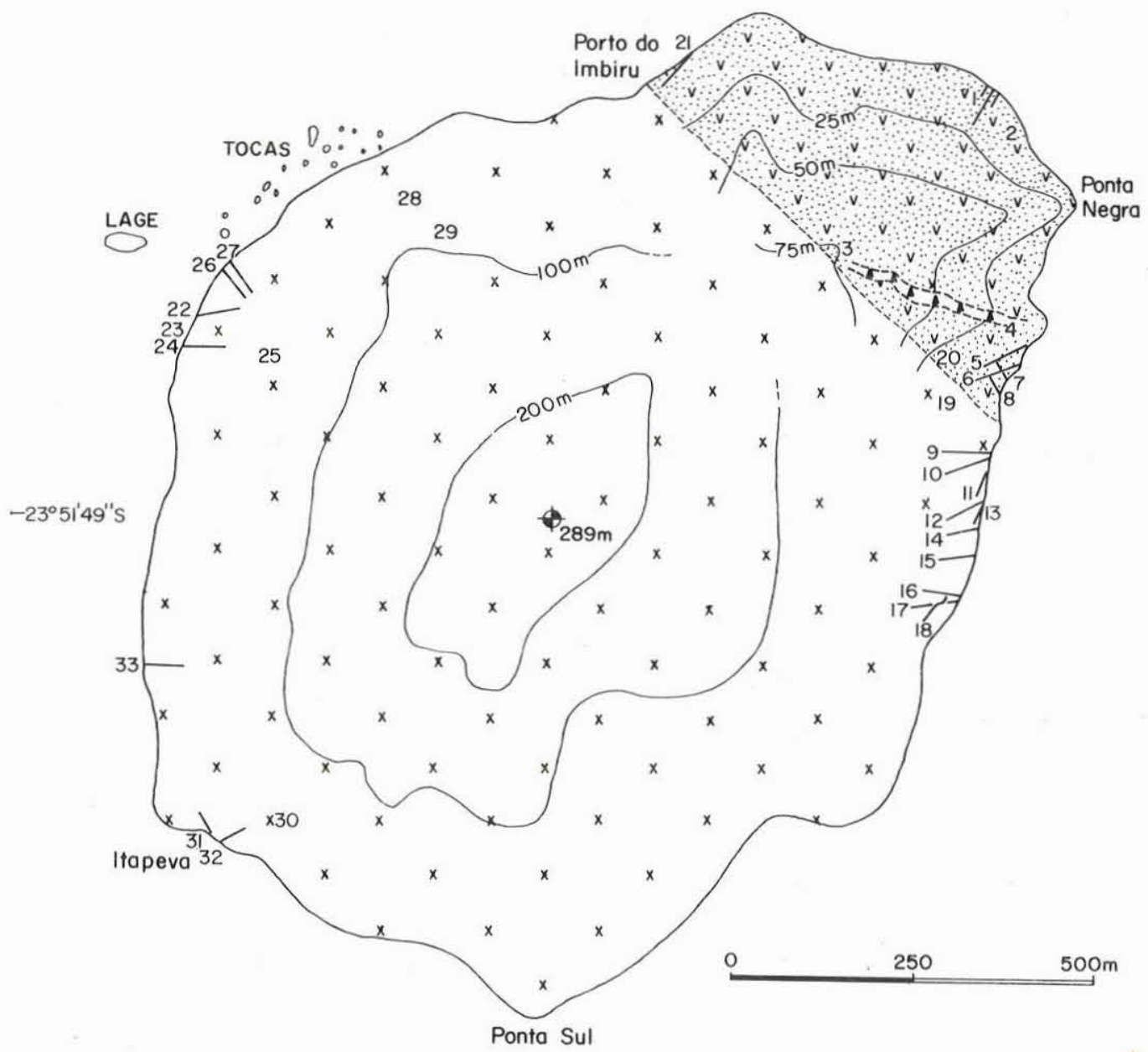

\section{CONVENÇÖÉS}

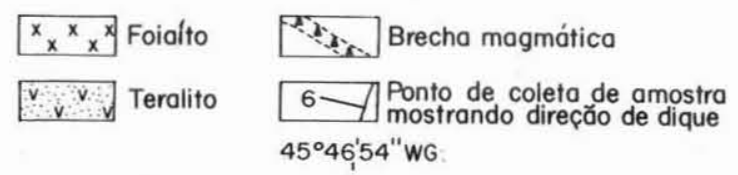

Figura 1 - Mapa geológico da Ilha do Monte de Trigo, litoral norte do Estado de São Paulo

mais próximo (um promontório entre as praias de Juqueí e Una) dista $10 \mathrm{~km}$. Seu contorno é elíptico, com o eixo maior dirigido para $\mathrm{N} 60^{\circ} \mathrm{E}$, medindo, ao longo deste, cerca de 1,5 $\mathrm{km}$. Normalmente a esse eixo, a maior largura da Ilha é $1,1 \mathrm{~km}$. A área plana, medida por integração gráfica, pode ser calculada num valor entre 1,25 e $1,30 \mathrm{~km}^{2}$. Observa-se, porém, um gradiente topográfico médio de $48 \%$, o que aumenta substancialmente a superficie real. Segundo a Folha de Salesópolis (IGG-Sp 1971, 1:50 000), o ponto culminante da Ilha se eleva a $289 \mathrm{~m}$ acima do nível do mar. Vegetação do tipo floresta tropical úmida se desenvolve de modo exuberante nas encostas da face sul e em alguns cílios de vale, na metade norte da Ilha. 
Anotamos alguns nomes de acidentes geográficos na Fig. 1. Ao norte, destaca-se, junto à costa, um certo número de lajes e pontas rochosas emersas, que são conhecidas por "lajes", (a maior) e "tocas" (as menores). Os extremos leste, sul e oeste receberam os nomes de, Ponta Negra, Ponta Sul e Itapeva, respectivamente. As habitações de cerca de uma dúzia de familias de pescadores com suas roças localizam-se junto ao Porto do Imbiru. $\mathrm{O}$ atracamento de embarcações se faz em uma enseada pedregosa nesse porto. No restante da Iha não se observam sinais de atividade humana, sendo a face sul quase totalmente coberta por vegetação alta. $O$ solo aparenta ser relativamente raso, aflorando freqüentes blocos e lajes de rochas claras por toda a vertente norte da Ilha, onde predomina vegetação rala.

Não existem praias arenosas. Toda a orla é rochosa. Em alguns pontos, observam-se penedos e lajes de rocha in situ, mas a maior parte da linha de costa, batida de ondas, é coberta de matacóes bem arredondados, com tamanhos desde pequenos até muito volumosos, com dezenas de metros cúbicos.

Geologia A área da Ilha é dividida de maneira muito nítida em dois domínios plutônicos contrastantes. Teralitos, rochas básicas muito escuras, dominam em $12 \%$ da Ilha, no seu ponto extremo a NE (Ponta Negra, cujo nome deriva-se, obviamente, da litologia local). Os restantes $88 \%$ são ocupados exclusivamente por foiaítos que afloram em rochas de tons claros, preferencialmente creme. $O$ contato entre os corpos leuco e melanocrático acha-se encoberto por vegetação, solo ou matacões rolados, mas foi inferido em levantamento de prancheta como correspondendo a aproximadamente, $\mathrm{N} 45^{\circ} \mathrm{W}$. As relações cronológicas entre ambos os corpos só poderiam ser deduzidas indiretamente no campo, e com grau de segurança limitado, como se vê adiante.

Acredita-se que os teralitos sejam intrusivos nos foiaítos. A primeira evidência surge das poucas estruturas observadas nos primeiros. Assim é que no ponto 5, imediações de contato, os teralitos se apresentam em camadas verticais dirigidas no rumo $\mathrm{N} 20^{\circ}$ a $45^{\circ} \mathrm{W}$, subparalelo à direção $\mathrm{N} 45^{\circ} \mathrm{W}$, que é a do contato geral foiaíto-teralito. $\mathrm{O}$ acamamento se define por alternância de faixas de até um decímetro de espessura, ora mais escuras, ora mais claras. Essa feição rítmica, bem conhecida em intrusões gábricas e freqüentemente atribuída à sedimentação gravitacional, no caso atual, parece ter outra origem, dada sua atitude vertical. Decorreria de movimentos fluxionares paralelos às paredes igualmente verticais, já mais.rígidas e frias dos foiaítos. A hipótese encontra, porém, um óbice; nesses casos, a granulação da rocha intrusiva tende a diminuir por efeito de chilling. $\mathrm{O}$ que se verifica em Monte de Trigo é o contrário, ou seja, granulação extremamente grosseira para o teralito, com augitas crescidas até 1 ou $2 \mathrm{~cm}$. Não temos uma explicação convincente para o fenômeno.

Outra consideração de ordem estrutural é fornecida pelas lajes e escarpas teralíticas do ponto 1. Aí se desenvolvem três boas direções de diaclasamento, aparentemente produzidas por mecanismo de resfriamento geometricamente condic onado à forma do maciço. Os três sistemas, verticais são: $\mathrm{N} 30^{\circ} \mathrm{E}, \mathrm{N} 80^{\circ} \mathrm{E}$ e $\mathrm{N} 60^{\circ} \mathrm{W}$. Essa ú.tima direção, subparalẹla ao conta to teralito-foiaíto, representaria um sheeting de resfriamento, implicando a natureza intrusiva do teralito.

Por ausência de exposições, não se observaram emissões in situ de apófises de um corpo em outro. Pouco se pode também concluir da natureza dos magmas que se consolidaram nos numerosos diques. No corpo teralítico, estão presentes diques de microteralito e teralito-pórfiro, tanto quanto de rochas claras; microfoiaíto e outras diferenciações sieníticas. No corpo foiaítico, igualmente foram coletadas amostras de diques com afinidades tanto foiaíticas (microfoiaítos, rhomb porphyry) como teralíticas (lamprófiros). 
As relações entre os diques também são ambíguas. No ponto 1, um microfoiaíto corta o corpo teralítico em um dique rico de xenólitos básicos, mas é também tangenciado e penetrado por novo corpo básico, um fino dique de lamprófiro microteralítico (Fig. 2). No ponto 7, o teralito é cortado por lamprófiro em dique NNW, o qual, por sua vez, é cortado (ponto 6) por outro dique lamprofirico a NEE, este, algo mais básico que o primeiro.

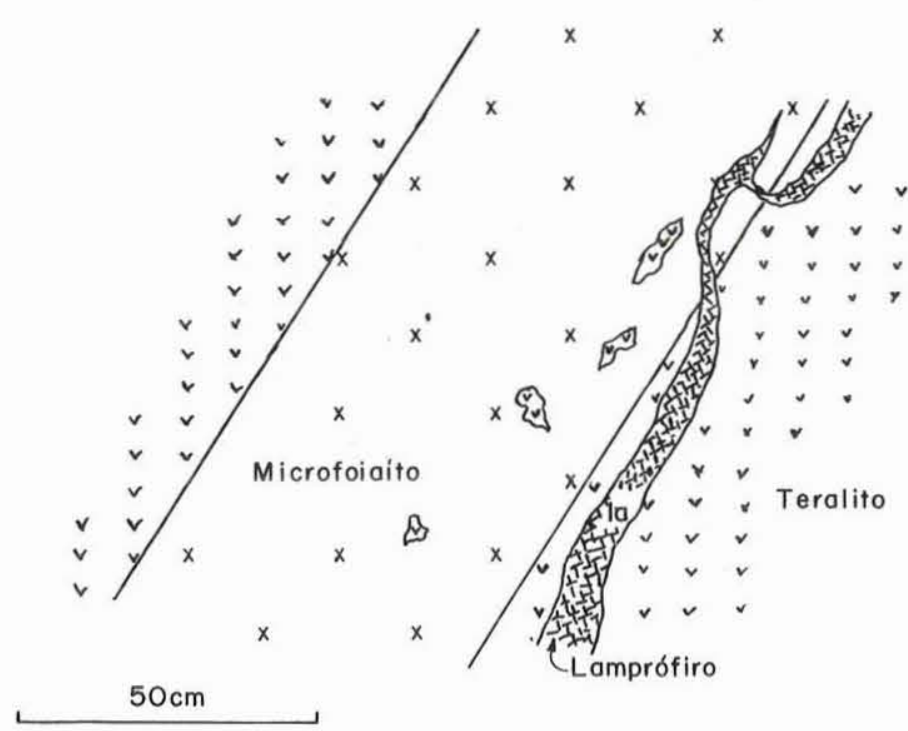

Figura 2 - Vista vertical superior de exposição no ponto 1

Os pontos 3 e 4 são os locais onde se observou interessante brecha magmática preenchendo fratura alargada em 5 a $15 \mathrm{~m}$, no macico teralítico. A direção N55 ${ }^{\circ} \mathrm{W}$ da brecha é bem próxima à direção de contato geral teralito-foiaíto. A brecha é rica de fragmentos de composição tanto foiaítica e teralítica como também granítica (ou gnáissica) e sua matriz é de natureza traquítica. Não há evidências claras de falhamento, parecendo que a massa subiu calmamente pela fratura gradualmente dilatada. Os blocos graníticos foram certamente trazidos de profundidade. A esse respeito mencione-se que, fora da zona de brechas e em toda a periferia da Ilha, observou-se apenas um bloco de gnaisse (aliás volumoso) encontrado entre matacões rolados de teralito, na costa, junto ao ponto 1. Trata-se de bloco rolado mais de cima, possivelmente libertado da própria brecha por desintegração da matriz traquítica.

Petrografia Em vista da heterogeneidade dos métodos de classificação e nomenclatura para rochas ígneas, resolvemos seguir, neste trabalho, as sugestões de Streckeisen, que nos pareceram simples e compatíveis com a maioria das concepções anteriores e atuais. $\mathrm{Na}$ descrição das rochas, julgou-se necessário acrescentar alguns dados ópticos de minerais, mas apenas aqueles que sirvam para melhor caracterizar o mineral e a rocha. Os métodos seguidos foram os microscópicos usuais.

1. PLUTONITOS Reservamos a classificação de plutonito somente para as rochas intrusivas de granulação grosseira e que ocorrem na Ilha de Monte de Trigo em formas de intrusão indefinidas (contatos encobertos e submersos). Nela se incluem os tipos litológicos dominantes teralitos e foiaítos. 
a) Teralitos (melateralitos). São rochas de granulação em média bastante grosseira e sempre escuras, praticamente negras. Nelas se distinguem cristais de augita, olivina e, subordinadamente, hornblenda e biotita. Os plagioclásios reúnem-se em agregados de granulação fina, intersticiais na trama de máficos.

Além do tipo normal (M-5 e MT-1), ocorrem também numerosas variedades mineralógicas e texturais, encontradas entre os matacões rolados na costa norte. Procuramos, entretanto restringir-nos na descrição, aos tipos amostrados in situ e que correspondem ao maior volume de ocorrências teralíticas. Essas rochas em geral obedecem à definição de teralitos acentuadamente máficos (índices de coloração entre 70 e 82), mas registraram-se composições variando para olivina melagabro (MT-20) com índice de coloração 90 (limite com piroxenitos) e até mesmo verdadeiros piroxenitos (MT av., índice de coloração, 93) que se classificariam perfeitamente como jacupiranguito. Essa é uma rocha relativamente comum entre os blocos rolados, pórfiros pretos onde se destacam fenocristais de nefelina esbranquiçada em grupamentos centimétricos. Nessa rocha, na Tab. I, somente a base melanocrática foi computada, mas o acréscimo de 2 a $4 \%$ de netelina de fenocristais não altera substancialmente sua conceituação petrográfica; no máximo a colocaria no limite entre melteigito e jacupiranguito.

Tabela I - Composições modais de teralitos e rochas afins (\% em volume)

\begin{tabular}{|c|c|c|c|c|c|}
\hline & \multirow[t]{2}{*}{$\begin{array}{c}\mathrm{M}-5, \\
\text { melateralito }\end{array}$} & \multirow[t]{2}{*}{$\begin{array}{c}\text { MT-1, } \\
\text { melateralito }\end{array}$} & \multicolumn{2}{|c|}{$\begin{array}{c}\text { MT-20, } \\
\text { olivina melagabro }\end{array}$} & \multirow[t]{2}{*}{$\begin{array}{c}\text { MT av., } \\
\text { jacupiranguito* }\end{array}$} \\
\hline & & & $1 .^{\mathrm{a}}$ & $2 .^{a}$ & \\
\hline Plagioclásio, $\mathrm{An}_{60}$ & 15 & 9 & 12 & 7 & س \\
\hline Feldspato alcalino & $\mathrm{pr}$ & pr & - & - & pr \\
\hline Nefelina & 15 & 3 & - & - & 7 \\
\hline Analcita & pr & pr & $\mathrm{pr}$ & pr & pr \\
\hline Mesóstasis & pr & 6 & - & - & pr \\
\hline Biotita & 2 & 3 & 4 & 4 & 1 \\
\hline Hornblenda & 4 & 16 & 8 & 18 & $\mathrm{pr}$ \\
\hline Augita & 44 & 52 & 47 & 49 & 75 \\
\hline Olivina & 13 & 8 & 28 & 19 & 4 \\
\hline Magnetita & 4 & 2 & 1 & 2 & 8 \\
\hline Apatita & 3 & 1 & pr & 1 & 5 \\
\hline Calcita & pr & pr & pr & pr & pr \\
\hline Serpentina, clorita & pr & $\mathrm{pr}$ & pr & pr & $\mathrm{pr}$ \\
\hline Índice coloração & 70 & 82 & 88 & 93 & 93 \\
\hline
\end{tabular}

*MT av.: composição calculada pela contagem de grãos em preparaçóes de rochá moída. Nas demais amostras deste trabalho, a contagem foi feita com contador de pontos em seções delgadas

Com a eventual aparição e incremento de feldspatos e/ou analcita, é previsível a ocorrência de tipos variando para teschenito, essexito ou glenmuirito, mas, de um modo geral, a julgar pelas comparações no campo, parece realmente predominar o teralito mafitico (melateralito).

O plagioclásio, ripiforme é normalmente uma labradorita-bitownita $\mathrm{An}_{70}$, mas observa-se zoneamento para capas externas até $\mathrm{An}_{30-40}$. O feldspato potássico, não detetado com segurança, parece fazer parte, em pequena proporção, de corpos mesostáticos intersticiais. A nefelina acha-se comumente alterada, total ou parcialmente, em agregados sericítico-carbonático-zeolíticos. Algumas amostras exibiam uma espécie de mesóstasis 
suja e mal-definida. Parece sèr formada essencialmente de nefelina esquelética ou pecilítica, interdigitada ou incluindo corpos caulinizados (feldspato potássico?), alterações carbonáticas, zeolíticas, cloríticas e numerosos pequenos prismas de apatita. Alguns minerais de cristalização anterior, especialmente hornblenda, podem também nela se incluirem e com ela reagirem hidrotermalmente.

O piroxênio é normalmente a titanaugita em grandes cristais de tendência idiomórfica, zonados, predominando externamente as capas titaníferas. Nas amostras sem nefelina (MT-20) todavia, o piroxênio não é violáceo, i.e., titanífero. A titanaugita, nas amostras de Monte de Trigo, tem as seguintes propriedades: $N_{y}=1,718,2 V_{z}=47^{\circ}$, dispersão $r$ maior que $v$ marcada no eixo próximo a $c$ e quase ausente no outro; $Z: c=46^{\circ}$.

A olivina, incolor, mas cravejada de opacos, também aparece em cristais tendendo ao idiomorfismo. $N_{y}=1,726$ e $2 V_{x}=80^{\circ}$ (dados obtidos em M-5), denunciam uma hialosiderita com $35 \%$ de faialita (Trögger).

A hornblenda pardo-vermelha é geralmente resultado de alteração de titanaugita, nesta se desenvolvendo em manchas periféricas ou clivagens internas. Algumas propriedades determinadas $\left(N_{z}=1,712, N_{z}-N_{x}=0,025,2 V_{x}=80^{\circ}, Z: c=8-12^{\circ}\right.$ e pleocroísmo $X$, amarelo-claro; $Y$, pardo; $Z$, pardo-avermelhado) correspondem com mais verossimilhança à kaersutita, como descrita em Deer et al. No caso de teralitos, são freqüentes as menções à barkevicita (Williams et al.), mas a gênese do mineral em tais rochas sugere composição titanífera mais apropriada à kaersutita.

Magnetita e apatita são os acessórios normais dos teralitos, aumentando muito sua porcentagem volumétrica nas rochas classificáveis como jacupiranguito. Carbonatos, provavelmente calcita e filossilicatos verdes do tipo de serpentina ou clorita, são produtos de alteração dos máficos.

A análise química da rocha M-5, executada por A. B. Oliveira acha-se indicada na Tab. II.

Tabela II

$\mathrm{SiO}_{2}-41,50$

$\mathrm{TiO}_{2}-1,70$

$\mathrm{Al}_{2} \mathrm{O}_{3}-13,80$

$\mathrm{Fe}_{2} \mathrm{O}_{3}-2,55$

$\mathrm{FeO}-10,08$

$\mathrm{MnO}-0,60$

$\mathrm{MgO}-12,46$

$\mathrm{CaO}-13,60$

$\mathrm{Na}_{2} \mathrm{O}-1,60$

$\mathrm{K}_{2} \mathrm{O}-1,22$

$\mathrm{H}_{2} \mathrm{O}^{-}-0,18$

$\mathrm{H}_{2} \mathrm{O}^{+}-\frac{0,46}{99,75}$

Tabela III - Análises modais de foiaítos

\begin{tabular}{lccccc}
\hline & MT-19 & MT-23 & MT-25 & MT-28 & MT-30b \\
\hline \hline Feldspato alcalino & 75 & 93 & 85 & 83 & 83 \\
Nefelina & 11 & 3 & 3 & 6 & 2 \\
Sodalita ou analcita & 1 & - & $\mathrm{pr}$ & $\mathrm{pr}$ & - \\
Alteração zeolítica & 3 & - & - & 1 & $\mathrm{pr}$ \\
Biotita & $\mathrm{pr}$ & - & 3 & - & $\mathrm{pr}$ \\
Anfibólio & 10 & 4 & 5 & 8 & 12 \\
Piroxênio & - & - & 4 & 1 & 3 \\
Magnetita & $\mathrm{pr}$ & $\mathrm{pr}$ & $\mathrm{pr}$ & 1 & $\mathrm{pr}$ \\
Apatita & $\mathrm{pr}$ & $\mathrm{pr}$ & $\mathrm{pr}$ & $\mathrm{pr}$ & $\mathrm{pr}$ \\
Titanita & $\mathrm{pr}$ & - & - & - & - \\
Calcita & $\mathrm{pr}$ & - & - & - & - \\
Índice de coloração & 10 & 4 & 12 & 10 & 15 \\
& & & & &
\end{tabular}

b) Foiaitos. Formam a litologia predominante da Ilha, aflorando em lajes esparsas em encostas ou, principalmente, em grandes blocos rolados e empilhados ao longo do perímetro costal da Ilha. A granulação é grossa e as cores são sempre claras, variando do amarelo-sujo ao creme-róseo. Distinguem-se a olho nu os máficos e os feldspatos, estes freqüentemente geminados, segundo Carlsbad. Entre os máficos, nota-se a presença constante de anfibólios acompanhados de biotita (por vezes em largas placas) e/ou piroxênio. 
Nefelina (ou eleolita) também pode ser observada em pequenos corpos acinzentados ou róseo-pardo-foscos.

Segundo Streckeisen, tais rochas devem ser denominadas de foiaítos, de preferência a nefelina-sienitos, mesmo porque, segundo Johannsen, aos foiaítos devem corresponder não as rochas de textura granitóide ou granular (nefelina-sienitos), mas sim as de textura traquitóide, com feldspato ripiforme, o que na realidade se verifica em Monte de Trigo.

O feldspato alcalino mostra alguma variação de aspecto. Em MT-19, é, em grande parte, homogêneo, inalterado e sem geminações. Ocasionalmente mostra albita em crescimento externo ou intercrescida irregularmente ou em pertita. A julgar pelo $2 V_{x}=80^{\circ}$ e $N_{y}=1,528$, trata-se de um ortoclásio sódico. Em MT-25 e MT-28, está presente o mesmo tipo de feldspato, agora incluindo manchas de ortoclásio potássico $\left(2 V_{x}=55^{\circ}\right)$ muito caulinizado, ao lado de outras manchas com geminação albita bem formada. Nessas duas amostras, o feldspato sódico-potássico original encontra-se em visível processo de demisturação em seus componentes alcalinos, os quais, ocupam preferencialmente as bordas dos cristais. Em MT-23 e MT-30, o feldspato alcalino é um mosaico exibindo pelo menos três composições em patches. A pertita está ausente ou rara, bem como o ortoclásio potássico. Nas manchas, observam-se variações de $2 V_{x}\left(50-80^{\circ}\right)$, alteração, birrefringência e geminação revelando possivelmente variações nas proporções mútuas de componentes potássico e sódico (também cálcico?).

A nefelina forma cristais isolados na trama da rocha, sempre parcial ou completamente alterada em produtos secundários (sericita, zeolitos, calcita, gibbsita).

O piroxênio dos foiaítos é um diopsídio sódico, verde-claro em seção. Ocorre em grãos isolados ou incluídos em biotita ou, ainda, capeados e substituídos parcialmente por anfibólio sódico. $N_{y}=1,72$ e $2 V_{z}=75^{\circ}$ apontam um diopsídio com $20 \%$ de moléculas egirínicas.

$\mathrm{O}$ anfibólio predominante nessas rochas é um tipo muito carregado nas cores verde-escura ou pardo-escura $(Z)$, pardo-escura $(Y)$ e pardo-clara $(X)$. As propriedades ópticas são variáveis; $2 V_{x}=40-70^{\circ}$, v maior que $r, N_{z}=1,71-1,72, Z: c=5-12^{\circ}, Y=b$, indicando a variedade barkevicita, como definida em Deer et al. Em capas externas, esse anfibólio passa freqüentemente a termos verde-escuros, provavelmente mais sódico-férricos. Nesse caso, o $2 \mathrm{~V}=0^{\circ}$, ou $0-20^{\circ}$, com plano dos eixos ópticos perpendicular a $b$ e com valores $Y: c=0-5^{\circ}$. Essas capas teriam composição próxima a ferro-hastingsita ou seriam variedade de arfvedsonita, recentemente reconhecida.

Biotita é do tipo pardo, por vezes alaranjado (sódico? wodanita?). Calcita e zeólitos, especialmente natrolita e analcita são secundários intersticiais. Observaram-se também raros grãos isótropos associados a feldspatos. Dada sua pequena freqüência não foi tentada uma diferenciação microquímica entre analcita e sodalita. Magnetita e apatita são acessórios primários quase sempre inclusos em anfibólio ou biotita. Titanita é muito rara $\mathrm{e}$ zircão não foi identificado com segurança.

2. ROCHAS HIPABISSAIS Na Ilha de Monte de Trigo são numerosos os exemplos de rochas intrusivas que caberiam na classificação de hipabissais. Com exceção de raras diferenciações pegmatóides (não abordadas neste trabalho), são todas rochas bem mais finas que o hospedeiro teralítico ou foiaítico. Algumas têm mesmo aspecto afanítico, revelando possíveis condiçסes de cristalização em ambiente subsuperficial. Esse é especialmente o caso de muitos lamprófiros e alguns pórfiros mais leucocráticos (rhomb porphyry). A ocorrência observada é invariavelmente a de diques subverticais, algo irregulares (sinuosidades) no mergulho. Em um mesmo dique, a espessura é bem uniforme, mas de dique para dique, foi encontrada uma variação de. espessura entre 5 e $150 \mathrm{~cm}$, com maior freqüência em 
torno de $40 \mathrm{~cm}$. Apenas a brecha magmática, um corpo tabular com 5 a $15 \mathrm{~m}$ foge a essa regra.

Em 25 medidas efetuadas, observou-se uma tendência para os diques se situarem na direção NE-SW $(17$ medidas $=60 \%)$. Se, entretanto, as medidas se redistribuírem por setores de 20 graus azimutais, a maior freqüência $(6$ medidas $=24 \%)$ corresponderia a $\mathrm{N} 60$ a $80^{\circ} \mathrm{E}$, seguido de outro máximo ( 4 medidas $=16 \%$ em $\mathrm{N} 20$ a $40^{\circ} \mathrm{W}$. O padrão não é claro, mas, aparentemente, o magma hipabissal preencheu um sistema retangular de fraturas verticais nas rochas plutônicas sólidas.

a) Hipabissais microfaneríticas leucocráticas: microfoiaitos. São rochas de granulação média ou fina, tonalidades claras (cinza, rósea ou creme), que cortam indiferentemente teralitos ou foiaítos. Alguns, por sua textura pavimentosa (MT-1a) ou escassez de máficos (MT-2, MT-5) poderiam ser considerados diferenciações aplíticas de foiaítos. Todavia, no caso geral, os microfoiaítos não são mais leucocráticos que os termos grosseiros e suas texturas nada têm de aplíticas. Seriam mais bem definidas como traquitóides, com os feldspatos ripiformes assumindo disposição subparalela entre si e aos contatos dos diques. Embora comumente afíricos, foram também observados microfoiaítos de tendência porfíítica (MT-26) bem como outros nitidamente porfiríticos ou glomero-porfiríticos (MT-15) exibindo fenocristais maiores de feldspato e manchas de nefelina poiquilítica.

Tabela IV - Análises modais de microfoiaítos

\begin{tabular}{lccccccc}
\hline & MT-1a & MT-2 & MT-5 & MT-15 & MT-22 & MT-26 & MT-27 \\
\hline \hline Feldspato alcalino & 61 & 67 & 72 & 75 & 75 & 75 & 69 \\
Nefelina & 26 & 21 & 18 & 13 & 12 & 17 & 15 \\
Sodalita ou analcita & pr & 10 & pr & 3 & 3 & pr & - \\
Zeólitos & - & - & 6 & 2 & - & - & - \\
Biotita & - & - & $\mathrm{pr}$ & $\mathrm{pr}$ & - & $\mathrm{pr}$ & 1 \\
Anfibólio & - & - & $\mathrm{pr}$ & 3 & 5 & 7 & 15 \\
Piroxênio & 11 & 2 & 2 & 3 & 4 & $\mathrm{pr}$ & $\mathrm{pr}$ \\
Magnetita & $\mathrm{pr}$ & $\mathrm{pr}$ & 2 & 1 & 1 & 1 & $\mathrm{pr}$ \\
Apatita & 2 & $\mathrm{pr}$ & - & $\mathrm{pr}$ & - & $\mathrm{pr}$ & - \\
Titanita & $\mathrm{pr}$ & $\mathrm{pr}$ & - & $\mathrm{pr}$ & $\mathrm{pr}$ & - & $\mathrm{pr}$ \\
Zircão & $\mathrm{pr}$ & $\mathrm{pr}$ & $\mathrm{pr}$ & - & - & - & - \\
Eṕdototo & $\mathrm{pr}$ & $\mathrm{pr}$ & - & - & - & - & - \\
Calcita & - & - & $\mathrm{pr}$ & $\mathrm{pr}$ & - & - & - \\
Indice de coloração & 13 & 2 & 4 & 7 & 10 & 8 & 16 \\
\hline
\end{tabular}

O feldspato alcalino é aqui considerado a soma dos sódicos (albita) e potássicos (ortoclásio) em vários graus de demisturação. A albita pode se apresentar isolada (MT-15) ou formar micropertitas bem definidas, do tipo "tigrado" (MT-la) ou manchado irregular. mente (MT-5, MT-15). Freqüentemente, porém, o que se observa é um feldspato límpido e homogêneo (salvo por geminação Carisbad) com $N_{y}=1,526$ e $2 V_{x}=70$ a $80^{\circ}$, o que indica ortóclásio com 30 a $40 \%$ de moléculas sódicas (Trögger). Nesse mineral, certamente uma criptopertita, é comum observar-se finíssima estriação ou tremulação de extinção sobre 001 , em direções coincidentes com os dois planos de prisma 110, ao mesmo tempo que finas franjas periféricas se encontram francamente demisturadas em seus componentes sódico e potássico. Nos casos de pertita definida ou feldspatos isolados, as proporçóes estimadas são de 2 feldspato sódico para 3 feldspato potássico. 
A nefelina forma grãos intersticiais ou irregulares, mesmo quando cresce poiquiliticamente em tamanhos bem maiores que os feldspatos (MT-15). Pode ocorrer fresca ou em qualquer grau de alteração, havendo casos em que está totalmente substituída por gibbsita, analcita e óxidos de ferro. Sodalita parece estar presente como grãos arredondados incolores em MT-2. Nas outras amostras, o mineral incolor isótropo é francamente secundário e poderia corresponder à analcita.

O piroxênio dos microfoiaítos é, em geral, uma egirina-augita verde, contendo molécula egirínica entre 30 e $50 \%$. Todavia tipos quase isentos de molécula sódica ocorrem em MT-26 e MT-27 e ainda outro, rico de egirina (Eg 90$)$ aparece em MT-la. Formam cristais discretos arredondados ou maiores, poiquilíticos.

$\mathrm{O}$ anfibólio pardo do núcleo de cristais maiores em MT-27 corresponde ainda a uma barkevicita $\left(Y=b, Z: c=15^{\circ}, 2 V_{x}=40-60^{\circ}\right.$ ), mas as capas, mais carregadas no verde, bem como cristais menores verdes da matriz fina têm $2 \mathrm{~V}$ aproximadamente $0^{\circ}$ e apontam a tendência à mudança de orientação. Está claramente invertida nos pequenos cristais pardo-esverdeados a verde-escuros de MT-15, MT-22 e MT-26, com as propriedades $Z=b, Y: c=5-15^{\circ}, 2 V_{x}=0-30^{\circ} v$ maior que $r$ forte; pleocroísmo, $X$, pardo rosa; $Y$, verde-escuro; $Z$, pardo-esverdeado ou verde-escuro. Trata-se provavelmente de variedade de arfvedsonita.

A biotita é rara e corresponde também a uma variedade sódica, pelo que indica a tonalidade alaranjada de absorção em $X$.

Magnetita é acessório obrigatório e apatita, titanita, zircão e epídoto aparecem irregularmente. Na rocha $\mathrm{MT}-\mathrm{la}$, os quatro acessórios transparentes cristalizam-se em formas poiquilíticas, por vezes esqueléticas. As propriedades ópticas dos mesmos não se acham ainda perfeitamente determinadas, motivo pelo qual é possível que uma ou mais das espécies possam ser futuramente atribuídas a outros tipos de acessórios zirconíferos ou titaníferos, comuns em foiaítos.

Tabela V - Análises modais de fonólito e rhomb-porphyries

\begin{tabular}{|c|c|c|c|}
\hline . & $\begin{array}{l}\text { MT-8 } \\
\text { Fonó- } \\
\text { lito }\end{array}$ & $\begin{array}{l}\text { MT-9 } \\
\text { Rhomb- } \\
\text {-porph. }\end{array}$ & $\begin{array}{l}\text { MT-32 } \\
\text { Rhomb- } \\
\text {-porph. }\end{array}$ \\
\hline \multicolumn{4}{|l|}{ Fenocristais } \\
\hline Feldspato alcalino & 6 & 5 & 2 \\
\hline Feldspatóide & 4 & - & 1 \\
\hline Biotita & 2 & 3 & 1 \\
\hline Anfibólio & - & $\mathrm{pr}$ & 3 \\
\hline Piroxênio & - & $\mathrm{pr}$ & - \\
\hline Magnetita & - & pr & pr \\
\hline Apatita & - & pr & pr \\
\hline Soma & 12 & 8 & 7 \\
\hline \multicolumn{4}{|l|}{ Base } \\
\hline Feldspática & $41 ?$ & $65 ?$ & $66 ?$ \\
\hline Feldspatóidica & $33 ?$ & $-?$ & $8 ?$ \\
\hline Biotita & 6 & 15 & 6 \\
\hline Anfibólio & - & - & 1 \\
\hline Piroxênio (egirinico) & 8 & 12 & 12 \\
\hline Soma & $\overline{88}$ & $\overline{92}$ & $\overline{93}$ \\
\hline Índice de coloração & 16 & 30 & 23 \\
\hline
\end{tabular}

Tabela VI - Análise química (analista, A. B. Oliveira)

\begin{tabular}{lrr}
\hline & MT-1a & \multicolumn{1}{c}{ MT-32 } \\
\hline $\mathrm{SiO}_{2}$ & 58,12 & 58,20 \\
$\mathrm{TiO}_{2}$ & 0,42 & 0,23 \\
$\mathrm{Al}_{2} \mathrm{O}_{3}$ & 19,00 & 21,10 \\
$\mathrm{Fe}_{2} \mathrm{O}_{3}$ & 2,53 & 1,26 \\
$\mathrm{FeO}$ & 2,86 & 1,80 \\
$\mathrm{MnO}$ & 0,26 & 0,20 \\
$\mathrm{MgO}$ & 0,48 & $.0,36$ \\
$\mathrm{CaO}$ & 1,81 & 1,71 \\
$\mathrm{Na}_{2} \mathrm{O}$ & 5,98 & 6,72 \\
$\mathrm{~K}_{2} \mathrm{O}$ & 5,05 & 4,80 \\
$\mathrm{H}_{2} \mathrm{O}^{-}$ & 0,63 & 0,32 \\
$\mathrm{H}_{2} \mathrm{O}^{+}$ & 1,70 & 1,76 \\
& 98,84 & 98,46
\end{tabular}


b) Hipabissais afaniticas porfiriticas leucocráticas; fonólitos e "rhomb-porphyries". Essas rochas, relativamente raras na Ilha, são rochas cinzentas de granulação muito fina (afaníticas), salvo por seus fenocristais milimétricos. Estes podem ser tanto cristais máficos como siálicos.

O feldspato alcalino dos fenocristais é normalmente um anortoclásio, como se verifica pelos índices, geminação fina e médio $2 \mathrm{~V}$. Todavia, em pelo menos um caso, MT-9 as partes centrais do mineral correspondem mais propriamente a um plagioclásio cálcico (labradorita). Em MT-9 e em MT-32, os fenocristais feldspáticos exibem a clássica forma rombóide (bem abaulada) que caracteriza os fenocristais de anortoclásio dos rhomb-porphyries.

As rochas dessa classe costumam apresentar feldspatóides (nefelina, analcita, sodalita, cancrinita), seja como fenocristais, seja como componentes da base, dificilmente distinguíveis de feldspatos.

A biotita, pardo-escura, cristaliza-se como fenocristal de maneira perfeitamente idiomórfica, mesmo para as faces prismáticas. Em geral é mais escurecida nas partes periféricas, onde há sinais de corrosão magmática. Como componente da base, o mineral é mais esverdeado.

O anfibólio, praticamente restrito a fenocristais, é um tipo vermelho-pardo que aparece com frequiência também entre os lamprófiros, a kaersutita. É também perfeitamente idiomórfico e, perifericamente, costuma passar à variedade verde.

$\mathrm{O}$ piroxênio é raro entre os fenocristais e, nesse caso, é uma titanaugita. Como componente da base, é muito difundido na forma de egirina ou egirina-augita. Apresentam-se, a seguir, para fins comparativos, os resultados de análises químicas em um microfoiaíto e em um rhomb-porphyry.

c) Hipabissais porfiriticas meso e melanocráticas: lamprófiros, sienobasaltos, microshonkinitos. Nessa categoria, enquadram-se todas as rochas de dique escuras. As mais comuns são os lamprófiros, só se excluindo a MT-7, um sienobasalto (basalto porfirítico com certa riqueza de feldspato alcalino) e as $\mathrm{MT}-30,31$ e 33 . Essas últimas foram aqui classificadas como microshonkinito.

Os microshonkinitos, antes de portịíticos, são, na realidade, inequigranulares, com pequena parte de sua mineralogia (anfibblios) apresentando dimensões sensivelmente menores que os restantes. A biotita é apenas levemente maior, em média, que os feldspatos, estes, com granulação entre 300 e 1000 mícrons. Os microshonkinitos não mostram claras relaçбes com os demais lamprófiros, não só por causa de sua mineralogia e textura discrepantes como também pela idade. Enquanto os típicos lamprófiros foram certamente injetados em época muito posterior à consolidação total da encaixante alcalina, já os microshonkinitos parecem ter"se formado no interior de sienitos em fase final de cristalização. A ocorrência obedece à forma tabular irregular (algo como schlierens), reentrante e embainhada nos contatos. Sua mineralogia é similar à da encaixante sienítica e há vestígios de ampla contaminação (xenocristais? porfiroblastos?) e troca de substâncias.

Já os lamprófiros formam diques de contatos muito nítidos, são sempre porfiríticos (salvo diferenciações afíricas locais) e a coloração é cinza-média a muito escura, até preta. A granulação da matriz é sempre muito fina, deixando a rocha macroscopicamente afanítica. Superficies desgastadas e levemente intemperizadas costumam ressaltar contrastes texturais em camadas paralelas longitudinais. Algumas são mais ricas de fenocristais, outras mais finas e compactas e outras, ainda, mais ricas de diferenciações de "bolhas"; micromiárolos, amígdalas, vacúolos. Essas cavidades são, em geral, pelo menos em parte, preenchidas por calcita, que, dissolvida, permite a formação de pequenas crateras superficiais.

Preferimos classificar os lamprófiros pelos tipos de máficos mais abundantes: anfibolio lamprófiro, olivina-piroxênio lamprófiro etc. A maioria possivelmente obedeça à definição 
Tabela VII - Análises modais de lamprofiros e rochas afins

\begin{tabular}{|c|c|c|c|c|c|c|c|c|c|c|c|c|c|c|c|}
\hline & MT-1b & MT-6 & MT-7 & $\mathrm{MT}+10$ & MT-11 & MT-12 & MT-13 & MT-16 & MT-17 & MT-18 & MT-24 & MT-29 & MT-30 & MT-31 & MT-33 \\
\hline \multicolumn{16}{|l|}{ Fenocristais } \\
\hline Feld. alc. & - & - & - & 1 & - & - & - & - & - & $\mathrm{pr}$ & - & _- & 1 & 1 & 1 \\
\hline Feld. plag. & - & - & 11 & - & - & - & - & - & - & - & $\mathrm{pr}$ & 1 & - & - & - \\
\hline Fóide & - & - & - & 1 & 1 & - & - & - & - & 1 & - & - & - & - & - \\
\hline Biotita & - & - & - & 2 & - & - & - & 2 & - & - & - & - & 6 & 10 & 11 \\
\hline Anfibólio & - & 1 & - & - & 1 & 8 & 1 & - & - . & 2 & 1 & 3 & - & - & - \\
\hline Piroxênio & 2 & $\hat{1}$ & 2 & 6 & 11 & 15 & 11 & 3 & 2 & 4 & pr & $\mathrm{pr}$ & - & - & - \\
\hline Olivina & 5 & - & - & - & 9 & 7 & 6 & 9 & 1 & - & $\mathrm{pr}$ & $\mathrm{pr}$ & - & - & - \\
\hline Magnetita & - & - & 1 & $\mathrm{pr}$ & - & 2 & - & - & 1 & 1 & $\mathrm{pr}$ & $\mathrm{pr}$ & - & - & - \\
\hline Apatita & - & - & - & 1 & - & - & $\mathrm{pr}$ & - & - & $\mathrm{pr}$ & $\mathrm{pr}$ & pr & - & - & - \\
\hline Soma & $\overline{7}$ & $\overline{2}$ & $\overline{14}$ & $\overline{11}$ & $\overline{22}$ & $\overline{32}$ & 18 & $\overline{14}$ & $\overline{4}$ & 8 & 2 & 4 & $\overline{7}$ & $\overline{11}$ & $\overline{12}$ \\
\hline \multicolumn{16}{|l|}{ Base } \\
\hline Feld. alc. & - & 40 & 20 & $?$ & $?$ & PP & PP & _- & PP? & PP & 28 & 40 & 52 & $?$ & $?$ \\
\hline Feld. plag. & 20 & 15 & 40 & - & $\mathrm{p}$ ? & PP & PP & 21 & Pp? & - & 35 & 16 & 2 & 48 & 53 \\
\hline Nefelina & 1 & 2 & - & $40 ?$ & p? & p? & - & - & $\mathrm{p}$ ? & $\mathrm{p}$ ? & pr & 8 & - & - & - \\
\hline Cancrinita & - & - & - & - & - & pr & - & - & - & - & pr & 2 & - & - & - \\
\hline Analcita & 2 & 7 & - & - & $p$ & $\mathrm{p}$ & $\mathrm{p}$ & 2 & - & PP & $\mathrm{pr}$ & 2 & - & - & - \\
\hline Muscovita & _- & - & - & - & $\mathrm{pr}$ & $\mathrm{pr}$ & - & - & - & - & - & - & - & - & - \\
\hline Biotita & 7 & - & pr & 17 & $\mathrm{p}$ ? & 3 & 2 & 10 & PP & $P$ & 9 & 4 & & & \\
\hline Anfibólio & 20 & 20 & - & - & P? & 13 & 22 & 25 & PP & - & 24 & 22 & 39 & 40 & 33 \\
\hline Piroxênio & 25 & 4 & 16 & 29 & p? & - & 8 & 19 & P? & PP & - & - & $\mathrm{pr}$ & - & 1 \\
\hline Magnetita & 18 & 2 & 7 & pr & $\mathrm{p}$ & $\mathrm{pr}$ & 3 & 8 & 10 & $\mathrm{p}$ & 2 & 2 & $\mathrm{pr}$ & 1 & 1 \\
\hline Apatita & $\mathrm{pr}$ & pr & 2 & 1 & $\mathrm{pr}$ & 3 & - & pr & pr & $\mathrm{p}$ ? & pr & pr & 1 & 1 & 1 \\
\hline Titanita & - & - & - & 2 & - & - & - & - & - & - & - & - & - & pr & $\mathrm{pr}$ \\
\hline Clorita & - & 3 & - & - & $\mathrm{p}$ & - & - & $\mathrm{pr}$ & $\mathrm{p}$ & $\mathrm{p}$ & $\mathrm{p}$ & $\mathrm{p}$ & - & - & - \\
\hline Carbonato & pr & 5 & 1 & $p$ & $\mathrm{p}$ & pr & pr & 1 & $\mathrm{PP}$ & - & $\mathrm{pr}$ & - & - & $\mathrm{pr}$ & рг \\
\hline Soma & $\overline{93}$ & $\overline{98}$ & $\overline{86}$ & 89 & $\overline{78}$ & $\overline{68}$ & $\frac{5}{82}$ & $\overline{86}$ & $\overline{96}$ & $\overline{92}$ & 98 & $\overline{96}$ & $\overline{93}$ & $\frac{18}{89}$ & $\frac{18}{88}$ \\
\hline Îndice de coloracão & 82 & 36 & 29 & 58 & 75 & 58 & 53 & 77 & 60 & 40 & 34 & 31 & 46 & 52 & 47 \\
\hline
\end{tabular}

MT-lb Olivina - piroxênio lamprófiro

MT-17 Olivina - piroxênio lamprófiro

MT-6 Anfibólio - piroxênio lamprófiro MT-18 Piroxênio - anfibólio lamprófiro

MT-7 Sieno - basalto

MT-10 Piroxênio - biotita lamprófiro . MT-29 Anfibólio lamprófiro

MT-11 Piroxênio - olivina lamprófiro MT-30 Microshonkinito

$\begin{array}{ll}\text { MT-12 Piroxênio - anfibólio lamprófiro } & \text { MT-31 Microshonkinito } \\ \text { MT-13 Piroxênio - olivina lamprófixo } & \text { MT-33 Microshonkinito }\end{array}$

TT-16 Olivenio - olivina lamprofía 

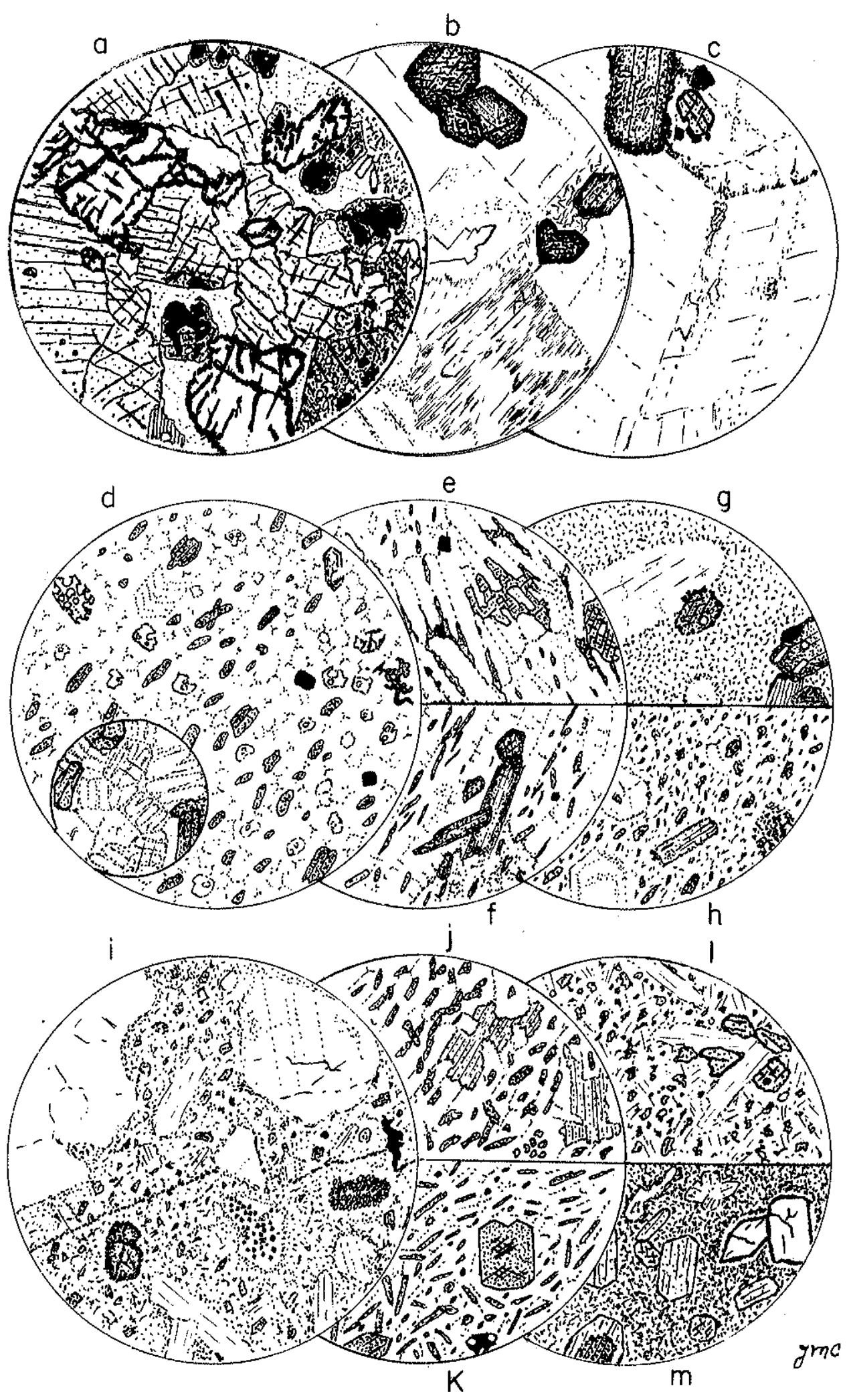
Figura 3 - Aspectos microscópicos de rochas da Ilha do Monte de Trigo. (Desenhos simplificados de seç̧ões observadas em luz paralela, polarizadores descruzados. Diâmetro do campo em todos, $5,5 \mathrm{~mm})$

(a) M-5. Melateralito. Ponta Negra. Olivinas subidiomórficas em alto relevo, clivagens opacificadas por magnetita. Titanaugita, abundante, médio relevo. Magnetita opaca rodeada de anfibólio que também substitui titanaugita. Interstícios claros ocupados por agregado de pequenas ripas de plagioclásio e alguma nefelina alterada. Tangenciando o campo, em cima e à direita, mesóstasis fina e suja.

(b) MT-19. Foiaito. Cristais grandes de feldspato alcalino. Anfibólio pardo, barkevicita. No centro, um vazio onde se cristalizou analcita. Em baixo, nefelina alterada.

(c) MT-28. Foiaíto. Cristais grandes de feldspato alcalino, algo alterados $\mathrm{em}$ caulim e analcita. A direita em cima. Nefelina quase fresca. Mineral escuro, anfibólio barkevicita e pequeno cristal de piroxénio à direita. Magnetita (opaco).

(d) MT-1a. Microfoiaito. Massa fina feldspático-nefelínica. Máfico mais comum é egirina. Acessórios; apatita, relativamente abundante, magnetita (opaco), epídoto (esquelético à esquerda em cima), zircâo e titanita (esqueléticos à direita). No círculo (aumento do anterior em 10 vezes), piroxênios, nefelina e feldspatos com típica estrutura pertitica em listas ("tigrada").

(e) MT-15. Microfoiaito. Feldspato alcalino ripiforme em textura traquitoide. Cristais maiores, relevo alto; egirina-augita. Nefelina poiquilitica em cima e em baixo à direita.

(f) MT-27. Microfoiaíto. Como o anterior. Máficos são aqui barkevicita com capas de arfvedsonita.

(g) MT-9. Rhomb-porphyry. Fenocristal rombóide arredondado de anortoclásio e outros de kaersutita (inclusões de apatita e magnetita) e biotita, imersos em matriz muito fina feldspático-feldspatóidica-egirínica.

(h) MT-8. Fonolito. Fenocristais de nefelina, feldspato alcalino, biotita, agregado máfico, agregado feldspatóidico. Matriz com egirina, biotita, feldspatos, nefelina.

(i) MT-3. Brecha magmática. Matriz traquítica muito fina. Poeira de magnetita e piroxênio diopsídico. Fragmentos de agregado quartzoso (em cima à esquerda), plagioclásio ś́dico (em cima à direita) plagioclásio cálcico (ripas de tamanho médio), titanaugita com coroa de reaçăo (em baixo à esquerda), agregado granular de diopsídio e quartzo (à direita). Vênula de titanita vermelha corta a seção.

(j) MT-33. Microshonkinito. Dois cristais maiores de biotita em uma massa de feldspatos ripiformes contendo pequenos cristais de anfibolio pardo.

(k) MT-29. Anfibólio-lamprofiro (monchiquito). Fenocristais bem idiomórficos de kaersutita em massa fina de feldspatos (plagioclásio e ortoclásio), nefelina e agulhas de anfibólio pardo capeado de verde. Alguma analcita. (l) MT-7. Sienobasalto. Textura glomero-porfirítica. Megacristais de plagioclásio agregado a piroxênio augítico. Massa fina contendo plagioclásio (capeado de ortoclásio), augita e magnetita.

(m) MT-13. Piroxênio-olivina lamprofiro (monchiquito?). Fenocristais idiomórficos de olivina (à direita) e piroxênio pouco titanífero, um deles rodeando núcleo de anfibblio pardo (em baixo). Massa fina contém feldspatos, analcita, piroxênio, biotita, magnetita e agulhas de anfibolio, este em maior quantidade.

de monchiquito. Um deles (MT-10), rico de nefelina, talvez seja um tjosito. A granulação muito fina e costumeira alteração hidrotermal dos lamprófiros impediu um exame acurado da massa fundamental e, por isso, uma classificação mais específica. Assim, os dados quantitativos são muito inseguros. De maneira geral, essas rochas se caracterizam por textura porfirítica tendendo à panidiomórfica. Os fenocristais são formados essencialmente por uma combinação de minerais máficos idiomórficos. Distinguem-se, entre estes, a olivina magnesiana $\left(2 \mathrm{~V}\right.$ próximo a $\left.90^{\circ}\right)$ em parte e, às vezes, totalmente substituída por óxidos de ferro, carbonato ou serpentina; clinopiroxênio (geralmente titanífero); clinoanfibolio pardo-avermelhado (kaersutita); biotita, magnetita e apatita. Feldspatos ou feldspatóides são muito raros como fenocristais.

$\mathrm{Na}$ massa fundamental geralmente se reconhecem piroxênios e/ou anfibólios e/ou biotita. Os dois primeiros podem se capear ou substituir-se por termos mais sódicos (egirina-augita, egirina, arfvedsonita). Em um caso verificou-se ortopirôxenio alterado. A matriz leucocrática é normalmente confusa e alterada, mas não são raras as manchas com micromiárolos, onde a granulação maior permite um melhor estudo microscópico. 
d) Brecha magmática. Uma das últimas, senão a última manifestação magmática registrada na região da Ilha do Monte de Trigo foi a que originou a brecha magmática que forma espesso dique na parte leste da Ilha, cortando teralitos e separando-os dos foiaítos. Sua composição é muito complexa e possivelmente variável de ponto para ponto. Uma seção delgada confeccionada de material retirado do alto do morro no ponto 3 (MT-3) mostra matriz feldspática muito fina, onde se dissemina uma poeira de magnetita e piroxênio diopsídico. Os fragmentos são muito variados nas dimensões, formas e natureza mineralogica. Combinando-se feições similares obtidas de amostra no ponto 4, costeiro, apontam-se, a seguir, algumas feições microscópicas mais importantes.

1. Corpos alongados ou traves de plagioclásio cálcico. As bordas são turvas e aparentemente mais cálcicas que o núcleo (andesina a labradorita). $O$ interior do plagioclásio costuma apresentar "gotas" espremidas de material fino, onde se identificaram diopsídio, poeira de magnetita e alguma biotita.

2. Corpos irregulares de plagioclásio sódico (oligoclásio) sericitizado e superficialmente corroído.

3. Agregados quartzo-feldspáticos grosseiros.

4. Biotita fibrosa, pardo esverdeada, de baixa birrefringência, coroada de diopsídio.

5. Agregados contendo bastőes de diopsídio e quartzo, coroando núcleos de magnetita.

6. Titanaugita rodeada por agregado de diopsídio e magnetita.

7. Hiperstênio alterado nos contornos e clivagens, para biotita de baixa birrefringência. O conjunto é contornado por agregado granular de diopsídio.

8. Numerosos pequenos cristais poiquilíticos de diopsídio.

9. Magnetita em grãos irregulares, grandes e pequenos.

10. Agregado fino quartzo-feldspático-carbonático.

11. Cristais de biotita verde fibrosa com contorno sugestivo de antigo anfibólio. Coroada por agregado de diopsídio e magnetita.

12. Agregados de espinélio.

13. Titanita com cor de pleocroísmo vermelho-róseo-profundo. O exame microscópico revelou que minerais ou fragmentos de rochas seguramente teralíticas e graníticas e alguns, também, possivelmente de origem foiaítica, foram englobados por magma traquítico e reaquecidos. Os produtos de transformação pirometamórfica tendem a estabilizar-se em associações incluindo diopsídio, magnetita, plagioclásio cálcico, espinélio (quartzo em associações silicosas).

\section{BIBLIOGRAFIA}

DEER, W. A., HOWIE, R. A. e ZUSSMAN, J. - 1962 - Rock forming Minerals.' Longmans, Londres

JOHANNSEN A. - 1939 - A descriptive petrography of the igneous rocks. University of Chicago Press, Chicago

STRECKEISEN A. L. - 1967 - Glassification and nomenclature of igneous rocks. (Final report of an inquiry) N.Jb. Miner. Abh, 107, 2-3, 144-240 pp.

TROGGER W. - 1959 - Optischen Bestimmung der Gesteinsbildenden Minerale. Teil 1, Stuttgart WILliAMS H., TURNER, F.J. e GILBERT, C. M. - 1954 - Petrography. W. H. Freeman and Co., San Francisco 